\title{
PENYULUHAN SELF READINESS TERHADAP BENCANA KEBAKARAN PADA ANAK USIA DINI
}

\author{
Upik Elok Endang Rasmani \\ Pendidikan Guru Pendidikan Anak Usia Dini, Universitas Sebelas Maret \\ upikelok@staff.uns.ac.id \\ Siti Wahyuningsih \\ Pendidikan Guru Pendidikan Anak Usia Dini, Universitas Sebelas Maret \\ siti_w@staff.uns.ac.id

\section{Yuanita Kristiani Wahyu Widiastuti} \\ Pendidikan Guru Pendidikan Anak Usia Dini, Universitas Sebelas Maret \\ yuanita27@student.uns.ac.id
}

\begin{abstract}
Abstrak
Kebakaran merupakan suatu ancaman yang berbahaya dan dapat mengakibatkan hilangnya nyawa seseorang dan kerugian secara materi. Anak usia dini sangat riskan menjadi korban kebakaran maka di perlukan adanya penyuluhan dan pendampimpingan kepada anak sebagai bekal dalam mencegah jatuhnya korban jiwa. Penelitian ini di fokuskan pada kegiatan sosialisasi pemahaman anak usia dini terkait bahaya dan pencegahan kebakaran yang marak terjadi akhir-akhir ini. Penelitian ini menggunakan pendekatan kualitatif dengan model sosialisasi. Data di peroleh dengan observasi dan wawancara dengan menggunakan Google Form melibatkan narasumber yang terdiri dari kepala sekolah, guru kelas B. Penelitian ini mengungkapkan bahwa kegiatan sosialisasi pemahaman anak usia dini terkait bahaya dan pencegahan kebakaran sangat diperlukan sebagai upaya persiapan pencegahan dan bekal kesiapan anak dalam menghadapi bencana kebakaran yang dapat terjadi kapan saja.
\end{abstract}

Kata Kunci: pencegahan, kebakaran, anak usia dini.

\begin{abstract}
Fire is a dangerous threat and can result in the loss of a person's life and material loss. Early childhood is very risky to become victims of fire so there is a need for counseling and assistance to children as provisions in preventing casualties. This research is focused on the socialization of early childhood understanding of the dangers and prevention of fires that have occurred recently. This study uses a qualitative approach with a socialization model. The data was obtained by observation and interviews using Google Form involving resource persons consisting of the principal, teachers of class B. This study revealed that the socialization of early childhood understanding regarding the dangers and fire prevention is very necessary as an effort to prepare for prevention and provision of children's readiness to face fire disaster that can happen at any time. Keywords: prevention, fire, early childhood.
\end{abstract}




\begin{tabular}{|c|c|c|}
\hline \multicolumn{3}{|c|}{ Jurnal Warna : Jurnal Pendidikan Dan Pembelajaran Anak Usia dini. } \\
Maret 2020. Vol 06. No. 01
\end{tabular}

\section{PENDAHULUAN}

Kebakaran adalah api yang tidak terkendali yang meluap dan menyebabkan kerugian. Kerugian yang ditimbulkan dari kebakaran yaitu kerugian jiwa, kerugian materi, menurunnya produktivitas gangguan bisnis serta kerugian sosial (Ramli, 2010). Salah satu diantaranya adalah banyaknya korban jiwa dari kalangan anak-anak juga menjadi kerugian yang perlu mendapat perhatian. Padatnya penduduk, banyaknya bangunan semi permanen, instalasi listrik yang semrawut, serta kurangnya antisipasi warga merupakan beberapa faktor yang menyebabkan kebakaran. Kepala Dinas Pemadam Kebakaran (Damkar) Kota Surakarta, Gatot Sukanto mengatakan, kasus kebakaran sampai saat ini cukup banyak terjadi meskipun mengalami penurunan. Pemadam Kebakaran Kota Surakarta mencatat kasus kebakaran di kota Surakarta dari tahun ke tahun memang masih cukup tinggi hingga akhir juni 2019, mencapai sebanyak 27 kasus kebakaran yang meliputi kebakaran pabrik, rumah, lahan kosong dan sebagainya (Solopos, 2020).

Jumlah kasus kebakaran tiap tahun menjadi perhatian oleh pemerintah, diantaranya adalah kerugian yang ditimbulkan. Kerugian dapat berupa harta benda, kerusakan gedung hingga korban jiwa (Supriyanto \& dkk, 2018). Untuk mencegah kejadian kebakaran dan mengurangi dampak yang ditimbulkannya, diperlukan tingkat pengetahuan tentang api yang memadai. Generasi muda dapat menjadi agen perubahan dalam penanggulangan kebakaran. Penting bagi mereka untuk dibekali pengetahuan dan kesadaran sejak dini mengenai pentingnya mencegah kebakaran (Rashid, Muhammad, Jonemaro, \& Akbar, 2018). Semakin cepat dan tepat penanganan bencana kebakaran, maka kerugian yang timbul akibat kebakaran ini akan semakin kecil. Tidak terkecuali apabila bencana kebakaran terjadi di perumahan dan perusahaan.

Masa Usia dini merupakan masa keemasan dimana 50\% kecerdasan anak terjadi pada usia dini (Sujiono, 2009). Pada masa ini anak sangat kreatif dan berkembang, penting untuk diberikannya pemahaman mengenai apa saja penyebab dan bagaimana mencegah terjadinya kebakaran sejak usia dini, sehingga dapat menjadi dasar pemahaman dan dapat diterapkannya saat dewasa (Latif, 2014). Penyuluhan ini bertujuan untuk memberikan pengetahuan kepada anak usia dini mengenai bahaya kebakaran dan bagaimana upaya yang dilakukan untuk penanggulangan kebakaran. Penyuluhan penanggulangan kebakaran kepada anak usia dini ini penting untuk dilakukan agar nantinya apa yang diajarkan pada mereka dapat diterapkannya pada saat mereka 


\begin{tabular}{|c|c|c|}
\hline \multicolumn{3}{|c|}{ Jurnal Warna : Jurnal Pendidikan Dan Pembelajaran Anak Usia dini. } \\
Maret 2020. Vol 06. No. 01
\end{tabular}

dewasa. Sehingga nantinya jika mengalami musibah kebakaran atau menemui kejadian tersebut dapat melakukan penanggulangan kebakaran dan membantu memadamkan api sebelum petugas Damkar datang.

Penyuluhan adalah suatu proses atau cara yang dilakukan oleh seorang penyuluh untuk memberikan penerangan atau informasi kepada orang lain dari semula yang tidak tahu menjadi tahu dan yang tahu menjadi lebih tahu. Orang yang melakukan komunikasi penyuluhan disebut penyuluh (Mulyana, 2016). Seorang penyuluh diharapkan memiliki keahlian berkomunikasi yang baik, hal ini berguna agar orang yang disuluh atau diberi informasi akan mudah memahami apa yang diinformasikan. Unsur-unsur dalam penyuluhan berupa komunikator, pesan, saluran, komunikan dan efek. Pada masa usia dini sangat diperlukan suatu penyuluhan sikap self readiness khususnya bagi anak usia dini dalam mencegah atau kesiapan menghadapi bencana kebakaran yang dapat terjadi kapan saja dan dimana saja.

Self readiness atau sering dikenal sebagai kesiapan diri merupakan suatu kemampuan yang cukup, baik fisik dan mental (Pace, Alper, Burchinal, Golinkoff, \& Hirsh-Pasek, 2019). Kesiapan fisik berarti tenaga yang cukup dan kesehatan yang baik, sementara kesiapan mental, memiliki minat dan motivasi yang cukup untuk melakukan suatu kegiatan (Dalyono, 2005). Sedangkan menurut Hamalik (2008) juga berpendapat bahwa kesiapan diri merupakan tingkat atau keadaan yang harus dicapai dalam proses perkembangan perorangan pada tingkatan pertumbuhan mental, fisik dan sosial emosional. Bagi anak usia dini penyuluhan self readiness sangat di perlukan khususnya dalam pencegahan bencana kebakaran, karena pada masa ini anak dilatih dan dikembangkan pemahamannya terkait upaya mencegah bencana kebakaran dan bertindak sesuai dengan perilaku yang perlu dilakukan.

Tujuan dari penelitian ini adalah mengetahui kesiapsiagaan (self readiness) anak-anak dalam pencegahan bencana kebakaran. Penelitian ini juga dilakukan dalam bentuk sosialisasi yang dilakukan oleh penulis baik secara offline maupun online. Materi yang di berikan berupa bentuk video dan praktek secara langsung, diharapkan melalui penelitian ini, self readiness anak dapat meningkat khususnya dalam mencegah terjadinya bencana kebakaran yang dapat terjadi kapan saja

\section{METODE PENELITIAN}

Penelitian ini dilaksanakan di TK Dirasatul Aulad Jamaatul Ikhwan Surakarta yang terletak di pemukiman tengah kota Surakarta dan memiliki potensi bahaya kebakaran tinggi. Penelitian dilakukan 


\begin{tabular}{|c|c|c|}
\hline \multicolumn{3}{|c|}{ Jurnal Warna : Jurnal Pendidikan Dan Pembelajaran Anak Usia dini. } \\
Maret 2020. Vol 06. No. 01
\end{tabular}

dengan metode deskriptif kualitatif yaitu pengumpulan data anak terkait pemahaman self readiness terhadap bencana kebakaran pada anak usia dini dan melakukan penyuluhan terkait hal tersebut (Sugiyono, 2013). Sasaran peserta sosialisasi adalah siswa kelas B TK Dirasatul Aulad Jamaatul Ikhwan Surakarta dengan jumlah 15 siswa. Skema pelaksanaan sosialisasi di tujukkan pada gambar berikut

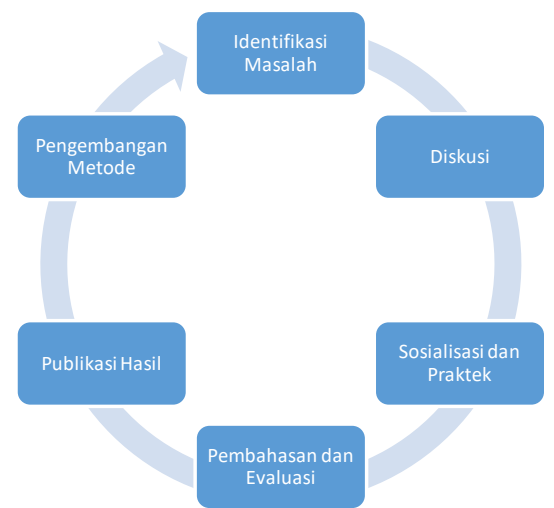

Gambar 1. Skema Pelaksanaan Sosialisasi

Pelaksanaan sosialisasi dilakukan dengan mengutamakan pemahaman siswa pada jenjangn pendidikan anak usia dini terhadap konsep terjadinya kebakaran dan cara penanggulangannya. Sosialisasi didukung dengan metode penyampaian materi dan diskusi yang menarik dan mudah dipahami oleh siswa. Kemudian dilanjutkan dengan praktik pemadaman api dengan menggunakan karung goni secara tradisional dan Alat Pemadam Api Ringan (APAR) dengan pengawasan. Evaluasi pemahaman terhadap sosialisasi dilakukan dengan diskusi lisan dan didukung dengan pemberian reward / hadiah

\section{HASIL DAN PEMBAHASAN}

Kebakaran adalah api yang tidak terkendali yang meluap dan menyebabkan kerugian. Kerugian yang ditimbulkan dari kebakaran yaitu kerugian jiwa, kerugian materi, menurunnya produktivitas, gangguan bisnis serta kerugian sosial (Ramli, 2010). Salah satu diantaranya adalah banyaknya korban jiwa dari kalangan anak-anak juga menjadi kerugian yang perlu mendapat perhatian. Untuk menekan kerugian yang di timbulkan dibutuhkan penyuluhan terkait kesiapan (self readiness) khususnya untuk anak usia dini dalam menghadapi mencegah bahaya kebakaran yang sewaktu-waktu dapat muncul

Penyuluhan adalah suatu proses atau cara yang dilakukan oleh seorang penyuluh untuk memberikan penerangan atau informasi kepada orang lain dari semula yang tidak tahu menjadi tahu dan yang tahu menjadi lebih tahu (Rasyid, 2011). Orang yang melakukan komunikasi penyuluhan disebut penyuluh. Seorang penyuluh diharapkan memiliki keahlian berkomunikasi yang baik, hal ini berguna agar orang yang disuluh atau diberi informasi akan mudah memahami apa yang diinformasikan. Unsur-unsur dalam 


\begin{tabular}{|c|c|c|}
\hline \multicolumn{3}{|c|}{ Jurnal Warna : Jurnal Pendidikan Dan Pembelajaran Anak Usia dini. } \\
Maret 2020. Vol 06. No. 01
\end{tabular}

penyuluhan berupa komunikator, pesan, saluran, komunikan dan efek.

Menurut Slameto (2010), kesiapan diri merupakan keseluruhan kondisi yang membuatnya siap untuk memberi respon atau jawaban dodalam cara tertentu trhadap suatu kondisi atau situasi. Penyesuaian kondisi pada suatu saat akan berpengaruh pada kecenderungan memberi respon. Secara sederhana kesiapan diri (self readiness) diartikan sebagai suatu kondisi yang dimiliki oleh seseorang dalam mempersiapkan diri baik secara mental, fisik maupun emosional sebagai prasyarat untuk menghadapi keadaaan yang akan datang (Eisenberg, Valiente, \& Eggum, 2010)

Masa usia dini sering disebut dengan istilah masa golden age atau masa emas. Pada masa ini hampir seluruh potensi anak mengalami masa peka untuk tumbuh dan berkembang secara cepat dan hebat. Penyuluhan self readiness kepada anak usia dini kaitannya dengan pencegahan bahaya kebakaran sangat cocok diberikan karena pada masa ini apabila anak di berikan stimulasi secara intensif dari lingkungannya, maka anak akan mampu menjalani tugas perkembangan dengan baik dan mencapai apa yang di harapkan dari tindakan tersebut baik sekarang hingga kedepannya.

Penyuluhan yang diberikan kepada siswa kelas B TK Dirasatul Aulad Jamaatul
Ikhwan Surakarta dilaksanakan diawali dengan melakukan observasi kepada guru dan kepala sekolah terkait kesiapsiagaan bencana kebakaran yang dilakukan oleh TK melalui google form dan melakukan observasi kepada anak dengan menggunakan media virtual room mengenai pengetahuan terkait upaya yang dilakukan oleh anak ketika menghadapi kebakaran. Selanjutnya data yang dikumpulkan di analisis oleh peneliti dan disusun sesuai dengan keperluan yang dibutuhkan oleh anak. Penyuluhan Self readiness terkait pencegahan bencana kebakaran pada anak usia dini dilakukan dengan cara cara pelaksanaan secara online yaitu dengan menggunakan video dan juga penyuluhan model video meeting dan dan penugasan kepada anak terkait apa yang telah diterimanya melalui penyuluhan yang dilakukan.

Materi yang diberikan kepada anak berupa pengajaran terkait kiat-kiat khusus dalam mencegah dan menghadapi bencana kebakaran yang dapat terjadi kapan saja materi tersebut berupa mengajarkan anak untuk merangkak atau berguling di tanah agar tidak terkena sambaran api (Lehna et al., 2014) dan membiasakan anak-anak dengan suara alarm jam dan hal-hal yang harus dilakukan ketika mendengarkan alarm tersebut (Links \& Questions, 2016) Selain itu mengajak anak apabila melihat gumpalan asap untuk segera menjauh dari 


\begin{tabular}{|c|c|c|}
\hline \multicolumn{3}{|c|}{ Jurnal Warna : Jurnal Pendidikan Dan Pembelajaran Anak Usia dini. } \\
Maret 2020. Vol 06. No. 01
\end{tabular}

tempat tersebut dan mencari perlindungan (Ashari, Prastiwi, Annabila, Rahmadani, \& Kusuma, 2018). Sekolah hendaknya Menyediakan alat pemadam kebakaran sederhana yang dapat digunakan sewaktuwaktu apabila peristiwa kebakaran terjadi sehingga dapat segera dicegah dan mengurangi jatuhnya korban jiwa Selain itu sekolah juga perlu untuk menyimpan korek api atau zat yang mudah terbakar lainnya di tempat yang aman jauh dari jangkauan anak-anak sehingga tidak dak berpotensi untuk menimbulkan bencana kebakaran. Sekolah juga hendaknya senantiasa melakukan simulasi kebakaran kepada anak minimal dua kali dalam satu tahun di mana dengan simulasi yang dilakukan maka anak akan terbiasa mendengarkan bunyi alarm kebakaran dan bersikap app siap untuk melaksanakan pencegahan kebakaran dan perlindungan diri terhadap bencana kebakaran.

Pemaparan terkait penyuluhan self readiness diberikan dalam bentuk video dan juga dalam bentuk presentasi secara online kepada anak maupun guru sehingga anak dapat memahami apa yang diharapkan terkait penyuluhan kesiapsiagaan diri dalam mengatasi bencana kebakaran.

\section{PENUTUP}

\section{Kesimpulan}

Berdasarkan pemaparan di atas dapat disimpulkan bahwa penyuluhan kesiapan diri untuk anak usia dini dalam mencegah bahaya kebakaran sangat penting Hal ini disebabkan pada masa usia dini anak memasuki masa keemasan di mana anak peka terhadap setiap rangsangan atau stimulasi yang diberikan oleh lingkungannya dan dan Pada masa ini anak dibentuk pemahamannya terkait hal-hal baru yang berguna untuk masa depannya khususnya berguna untuk kesiapsiagaan anak dalam menghadapi bencana kebakaran Selain itu sekolah juga perlu memfasilitasi anak khususnya dalam penyuluhan atau sosialisasi bencana kebakaran yang dapat dilakukan setiap 1 tahun minimal 2 kali karena mulai dari sekolah anak memahami terkait pengembangan diri dan pengetahuan mencegah terjadinya kebakaran dan melakukan penyelamatan apabila terjadi kebakaran

\section{Saran}

Kegiatan penyuluhan self readiness terkait bahaya kebakaran perlu banyak dilakukan agar anak dan orang tua bahkan guru dapat mempersiapkan anak sigap dalam menghadapi bencana kebakaran yang sewaktu-waktu dapat terjadi 


\begin{tabular}{|c|c|c|}
\hline \multicolumn{3}{|c|}{ Jurnal Warna : Jurnal Pendidikan Dan Pembelajaran Anak Usia dini. } \\
Maret 2020. Vol 06. No. 01
\end{tabular}

\section{DAFTAR PUSTAKA}

Ashari, M. L., Prastiwi, T. R., Annabila, A. R., Rahmadani, N. R., \& Kusuma, A. D. P. (2018). Sosialisasi Kebakaran Dan Penangannya Pada Siswa Sekolah Dasar Di Surabaya Guna Meningkatkan SelfReadiness Terhadap Bencana Kebakaran. Jurnal Cakrawala Maritim, 1(1), 21-24. https://doi.org/10.35991/cakrawalamariti m.v1i1.428

Dalyono. (2005). Psikologi Pendidikan. Jakarta: Rineka Cipta.

Eisenberg, N., Valiente, C., \& Eggum, N. D. (2010). Self-regulation and school readiness. Early Education and Development.

https://doi.org/10.1080/10409289.2010.4 97451

Latif, M. (2014). Orientasi Baru Pendidikan Anak Usia Dini. Jakarta: Kencana Prenamedia.

Lehna, C., Janes, E. G., Rengers, S., Graviss, J., Scrivener, D., Knabel, T., ... Myers, J. (2014). Community partnership to promote home fire safety in children with special needs. Burns, 40(6), 1179-1184. https://doi.org/10.1016/j.burns.2013.12.0 19

Links, R. K., \& Questions, D. (2016). Food and Cooking Safety Activities for Students. USA: The Nemours Foundation/KidsHealth.

Mulyana, D. (2016). Ilmu Komunikasi Suatu Pengantar. Bandung: Remaja Rosdakarya.

Oemar, H. (2008). Perencanaan Pengajaran Bedasarkan Pendekatan. Sistem. Jakarta: Bumi Aksara.

Pace, A., Alper, R., Burchinal, M. R., Golinkoff, R. M., \& Hirsh-Pasek, K. (2019). Measuring success: Within and cross-domain predictors of academic and social trajectories in elementary school. Early Childhood Research Quarterly. https://doi.org/10.1016/j.ecresq.2018.04. 001

Ramli, S. (2010). In: Pedoman Praktis Manajemen Bencana. Jakarta: Dian Rakyat.

Rashid, N. M., Muhammad, E., Jonemaro, A., \& Akbar, M. A. (2018). Implementasi Permainan Pemadam Kebakaran Menggunakan Teknologi Virtual Reality. Jurnal Pengembangan Teknologi Informasi Dan Ilmu Komputer, 2(12),
6936-6941.

Rasyid, A. (2011). Komunikasi Penyuluhan. Riau: Pusat Pengembangan Pendidikan Universitas Riau.

Slameto. (2010). Belajar dan Faktor yang mempengaruhinya. Jakarta: Rineka Cipta.

Solopos. (2020, September 15). Berita Kebakaran. Solopos. Retrieved from https://www.solopos.com/tag/kebakaransolo

Sugiyono. (2013). Metode Penelitian Kuantitatif, Kualitatif, dan R\&D. Bandung: Alfabeta.

Sujiono, Y. N. (2009). Konsep Dasar Pendidikan Anak Usia Dini. Jakarta: Index.

Supriyanto, \& dkk. (2018). Analisis Kebijakan Pencegahan Dan Pengendalian Kebakaran Hutan Dan Lahan Di Provinsi Jambi. Pembangunan Berkelanjutan, 1(1), 94-104. 